\title{
The Economic Cost of ill Health due to Air Pollution: Evidence from Greece
}

\author{
Maria Panteli ${ }^{\dagger 1}$, Sofia Delipalla ${ }^{2}$ \\ 1,2Department of Balkan, Slavic and Oriental Studies, University of Macedonia, Thessaloniki, Greece
}

\begin{tabular}{l}
\hline ARTICLE INFO \\
\hline Article History \\
Received 24 May $2021 ;$ \\
Accepted 29 October 2021 \\
\hline JEL Classifications \\
I18, Q51, Q53
\end{tabular}

I18, Q51, Q53

Keywords:

Air Pollution; Health

Effects; Economic Cost,

Mortality and Morbidity

Cost; Healthcare Expenses;

Greece

\author{
ABSTRACT \\ Purpose: \\ Air pollution and its adverse health effects result in an economic cost to society. Given that \\ the burden of disease from air pollution is to a large extent preventable, estimation of the \\ magnitude of its economic cost is important. We estimate the economic cost of the health \\ impact from exposure to ground-level ozone, and ambient and household $\mathrm{PM}_{2.5}$ air \\ pollution, as well as their joint effects, in Greece.
}

Design/methodology/approach:

We analyze the economic cost of the health impact from air pollution using the Cost-ofIllness (COI) as well as the Willingness to Pay (WTP) approach.

Finding:

Based on the COI approach, air pollution attributable diseases resulted in a total economic cost of $€ 1.27$ billion in 2019, or 0.68 percent of GDP. Under the WTP approach, mortality cost is significantly higher.

Research limitations/implications:

In spite of some standard methodological limitations, giving a monetary value to the burden of disease from air pollution highlights the significance of curbing air pollution, providing at the same time guidance in prioritizing among various competing policy objectives. Air pollution abatement interventions can yield significant benefits for global health and the economy.

Originality/value:

To the best of our knowledge, this is the first study estimating direct and indirect costs of air pollution-attributable health consequences in Greece, using the most recent data for all specific-cause mortality and morbidity outcomes. Employing two alternative methodologies, COI and WTP, we provide a lower and an upper bound of the economic cost of air pollution, respectively. The COI estimates provide a financial measure of the potential gains (by age and gender) if air pollution were to be extensively mitigated. The WTP estimates are a starting point in a cost-benefit analysis evaluating certain environmental regulation policies. Our results and their policy implications could be a guide to other economies with similar characteristics and comparable air pollution levels with those in Greece.

\section{Introduction}

Since the second half of the past century, a tremendous increase in global population, the global pressure of increased economic activity, energy usage and pollution emissions (especially carbon emissions) have induced various crises, with the most obvious and pressing one being the climate crisis (Harris, 2019). The present times are increasingly defined by the need to tackle the 'grand challenges', including climate change, demographic issues, improvement of health and well-being for all, while promoting sustainable but also inclusive growth (Mazzucato, 2020). It has been advocated that the pressing need for action requires a reconsideration of the role of the government. It should not merely correct arising market failures, for example, due to negative externalities, but also advance on an active creation of markets confronting the most pressing issues and challenges faced by societies today, leading the way towards a green transition (Mazzucato and McPherson, 2018; Mazzucato, 2020).

This green transition requires a fast and extensive transformation in the fields of energy, management of ecosystems, investment in infrastructure and a redesign of governments' industrial policies, providing opportunities for green investment and innovation to tackle climate change and social inequalities (Mazzucato and McPherson, 2018; Galvin and Healy, 2020). For more on the proposed idea of a green new deal see, for example, Luke (2009), Custers (2010), Aşici and Bünül (2012), White (2019), and Galvin and Healy (2020). In line with this debate, our paper considers the important issue of environmental degradation and its negative consequences for human health due to air pollutants. According to the most recent round of the Global Burden of Disease Study (GBD 2019, 2020), air

${ }^{\dagger}$ Corresponding Author: Maria Panteli

Email: panteli@uom.edu.gr 
pollution is the fourth leading risk factor causing death and disability, contributing to the burden of disease worldwide. The World Health Organization (WHO) has estimated that 91 percent of the population around the globe is exposed to air pollution levels exceeding the WHO air quality guideline limit values. The joint health effects of ambient and household air pollution result in more than seven million premature deaths each year (WHO, n.d.), an estimate which can be considered conservative when compared to the findings of Burnett et al. (2018) and Lelieveld et al. (2019) regarding the impact of ambient air pollution. Lelieveld et al. (2019) find the mean per capita mortality rates in Europe to be higher than the global average, with the difference being even more pronounced in Eastern Europe.

Air pollution exposure (including ambient fine particulate matter $\left(\mathrm{PM}_{2.5}\right)$, household $\mathrm{PM}_{2.5}$ and ambient ozone air pollution) has been associated, among others, with upper and lower respiratory infections, lung cancer, stroke, ischemic heart disease, diabetes mellitus and chronic obstructive pulmonary disease (GBD 2019, 2020). The majority of these health conditions are non-communicable. Specifically, the estimated share of non-communicable diseases in the air pollution-related global disease burden is more than 70 percent (Landrigan et al., 2018). This suggests that interventions for air pollution abatement can yield significant benefits in global health.

Polluted air and its negative consequences for human health result in a significant economic cost. According to the Lancet Commission on pollution and health, diseases related to air pollution are responsible for productivity losses which in many low- and middle-income countries can be as high as 2 percent of their Gross Domestic Product (GDP) (Landrigan et al., 2018). Also, healthcare costs resulting from air pollution-attributable diseases are significant in both high- and middle-income countries, with estimated costs ranging from 1.7 percent to 7 percent of their total annual healthcare spending (Landrigan et al., 2018). Global economic cost of air pollution, measured in welfare terms, is estimated to reach many trillion US dollars each year (WHO and OECD, 2015; Landrigan et al., 2018), a cost which is projected to rise significantly in the coming decades (OECD, 2016).

In Greece, the issue of air pollution has been recurrent. In the beginning of the 2000s, the largest cities have been among the top 20 cities in Europe with the 'most days per year of poor air quality' (European Commission (EC), 2007, p. 116). In the decade from 2000 to 2010 , concentration levels of many air pollutants stabilized (or declined) due to a more widespread use of higher quality fuels, major investment in public transportation and the use of technologically enhanced road transport vehicles (European Environmental Agency (EEA), 2008; Organization for Economic Cooperation and Development (OECD), 2009). Concentrations of $\mathrm{PM}_{2.5}$ and ozone, however, remained persistently high (OECD, 2009). From 2010 onwards, a gradual improvement of air quality has been documented due to reduction of primary pollutant emissions, mainly driven by the Greek economic crisis but also by the obligations stemming from European legislation (National Centre for the Environment and Sustainable Development (NCESD), 2018). All recorded mean annual concentrations of $\mathrm{PM}_{2.5}$, however, exceeded the WHO guideline limit value of $10 \mu \mathrm{g} / \mathrm{m}^{3}$, although they did not exceed the European Union (EU) set air quality standard of $25 \mu \mathrm{g} / \mathrm{m}^{3}$ (WHO, 2006; EC, n.d.). Ground-level ozone concentrations also have had a less pronounced long-term improvement, due to regional climatological conditions which aid the manifestation of high concentration episodes (NCESD, 2018). The most recent health data available indicate that exposure to ambient and household $\mathrm{PM}_{2.5}$, as well as ambient ozone air pollution jointly, constituted the fifth leading risk factor causing death in Greece, in 2019, behind metabolic risks, tobacco use, dietary risks and non-optimal temperature (GBD 2019, 2020). During the same year, air pollution was the seventh leading risk factor causing disability. More than 90 percent of air pollution-attributable diseases are noncommunicable (GBD 2019, 2020). See Figures A1 \& A2, in Appendix A, for mortality and morbidity due to air pollution, by disease, gender and age.

As already noted, the burden of disease from air pollution is to a large extent preventable. To guide public policy to this end, estimation of the magnitude of the economic cost resulting from air pollution exposure is important. Such estimates for Greece, however, are scarce. Existing research has focused on particular metropolitan regions, and/or emissions and concentrations from certain activities or sectors. Specifically, Georgakellos (2007) estimated the external cost of various air pollutants from thermal power stations; Mirasgedis et al. (2008) estimated the cost of environmental damage from air pollution emitted from industrial activities in the greater area of Athens; Vlachokostas et al. (2012) calculated the social cost of the health impact of particulate matter ( $\left.\mathrm{PM}_{10}\right)$ and ozone air pollution in the greater area of Thessaloniki; Sarigiannis et al. (2015) estimated the economic cost of the health impact from exposure to $\mathrm{PM}_{10}$ air pollution resulting from biomass burning in Thessaloniki.

Estimates of the economic cost, in terms of mortality and morbidity, from exposure to many pollutants emitted from major industrial facilities in Greece are also included in a European study (EEA, 2011). Estimates from the Impact Assessment for the EC Integrated Clean Air Package (EC, 2013) show that the external cost resulting from air pollution reaches $€ 7$ billion (income adjusted, 2010) per year. A global study estimated mortality cost, resulting from exposure to ambient and household $\mathrm{PM}_{2.5}$ air pollution in Greece, to be equal to 7.1 percent of GDP in 2010 (WHO and OECD, 2015). The World Bank (WB) and the Institute for Health Metrics and Evaluation (IHME) found mortality cost to be equal to 8.55 percent of Greece's GDP, in 2013, when using the same methodology, the Willingness to Pay approach (WTP) (WB and IHME, 2016); using the Cost-of-Illness (COI) approach, economic cost due to mortality from air pollution was found to be 0.14 percent of GDP. The relative magnitude of the estimated cost in Greece, compared to the 142 countries included in the report, varied widely under the two alternative methodologies employed. Under the WTP method, Greece was found to be among the top ten countries with the highest mortality cost estimates, a result which is in contrast with the findings of the WHO and OECD (2015) study. On the other hand, under the COI method, more than 58 percent of the countries had a relatively higher estimate for mortality cost due to air pollution. The methodological assumptions, differences in health data, as well as differences in economic conditions, are of paramount importance and greatly influence economic cost estimates. 
Neither of the studies conducted by major international organizations focuses specifically on Greece nor does it calculate morbidity cost and healthcare expenditure due to air pollution. Our paper integrates the health impact from exposure to air pollutants with the strongest epidemiological evidence, regarding their negative health outcomes, while the spatial coverage concerns the whole country. We estimate the economic cost of air pollution, first, using a market-based methodology, the COI approach, which is one of the most common economic evaluation methods employed in the context of health economics (Tarricone, 2006; Jo, 2014). All cost components related to health impact of air pollution are taken into account, with estimates concerning not only ambient air pollution but also household air pollution from cooking with polluting fuels and technologies. The analysis is detailed, with cost estimates being offered by gender and age group for mortality and morbidity cost. The most recent data available on the burden of disease are used.

We estimate the cost of air pollution-related mortality with a non-market valuation method, as well, that is, the WTP approach. In the original application of the methodology, a stated preferences survey elicits people's WTP through the valuation of 'realistic, but hypothetical, [mortality] risk reduction scenarios' (Lindhjem et al., 2011, p. 1382). The resulting measure, commonly referred to as value of statistical life (VSL), is essentially a trade-off rate between wealth/money and fatality risk (Viscusi, 2010; Lindhjem et al., 2011), serving as a reference point against which governments can assess the benefits of policies aimed at mortality risk reductions (Viscusi, 2003). The alternative scenario is an implicit and arbitrary valuation through policy decision-making, a process which is often non-transparent and can potentially result in inefficient resource allocation (Lindhjem et al., 2011).

Due to the lack of a primary WTP survey for Greece, we make use of the OECD-recommended VSL with the necessary adjustments made (OECD, 2012, 2014). ${ }^{1}$ The OECD-recommended VSL is based on a meta-analysis of 92 published research studies on stated preferences within the context of environment, health and traffic (OECD, 2012). The estimated monetary value is best suited for welfare cost analysis (see, Hunt, 2011; OECD, 2012, 2014; Narain and Sall, 2016 and references therein) and represents welfare losses to the Greek society resulting from air pollutioninduced mortality.

By employing the two alternative methodologies, COI and WTP, we provide a lower and an upper bound of the economic cost of air pollution in Greece, respectively (Cropper, 2000; Meisner, 2015; Narain and Sall, 2016). Our estimates, under the COI approach, can be viewed as a financial measure of the gains that would have been achieved if air pollution were to be extensively mitigated in the country. WTP estimates, on the other hand, can be used as a starting point in cost-benefit (CB) analysis for evaluating environmental regulation policies aimed at reducing mortality risk due to air pollution. In general, giving a monetary value to the burden of disease from air pollution can redirect the allocation of resources in favour of further curbing air pollution, and highlights the significance of the issue among various competing policy objectives and priorities. Our qualitative results and their policy implications are expected to be of international relevance. The estimates could serve as a guide to economies with similar characteristics and comparable air pollution levels with those in Greece.

\section{Materials and Methods}

We estimate the economic cost of the health impact resulting from exposure to ground-level ozone, and ambient and household $\mathrm{PM}_{2.5}$ air pollution, as well as their joint effects (total air pollution). Both the COI and the WTP approaches are employed.

\subsection{Cost-of-Illness Approach}

The COI method has been developed originally by Rice (1967) and Rice et al. (1985), employed thereafter by numerous studies valuing the health burden of a disease. The information provided by the COI estimates can guide the formulation and prioritization of policies and interventions in the healthcare system and, ultimately, guide allocation of healthcare resources for policy efficiency, given the budgetary constraints (Jo, 2014). In this context, the COI framework has been frequently used in the analysis of the health burden due to air pollution in various countries or even sub-regions within countries (e.g., Alberini and Krupnick, 2000; Croitoru et al., 2010; Patankar and Trivedi, 2011; Meisner et al., 2015; Sander et al., 2015; Lu et al., 2016; Bherwani et al., 2020). To the best of our knowledge, such a detailed analysis for Greece does not exist.

According to COI, there are direct and indirect costs. Direct cost includes healthcare expenses for diagnosis and treatment of diseases related to air pollution exposure. The associated non-healthcare expenses, such as transportation expenditure to hospitals and expenses for healthcare providers, are not included (as usual) due to lack of data.

Direct cost, or attributable health expenses, is estimated according to the formula

$$
P A E_{j}=P A F_{j} \times T H C E
$$

where $P A E$ is health expenses attributable to air pollution by air pollution subcategory $j, P A F$ is mean estimated air pollution attributable fraction based on number of deaths by $j$, and THCE is total healthcare spending, including all domestic and international financing sources in 2019.

\footnotetext{
${ }^{1}$ We have pinpointed a single study employing a contingent valuation method to elicit WTP for a marginal reduction in the risk of premature mortality due to air pollution in the Greek context by Vlachokostas et al. (2011). However, in this study, WTP is estimated only for the city of Thessaloniki and therefore it was deemed inappropriate to be used for the whole country.
}

DOI: 10.25103/ijbesar.143.07 
Indirect cost measures productivity losses stemming from morbidity and early mortality due to illnesses attributable to air pollution exposure. The indirect cost component is quantified with the Human Capital method. Human life is valued through the stream of present and future market earnings and the resulting economic cost of a disease is measured through the disruption of this stream of productive output by morbidity and premature mortality (Max et al., 2004).

Mortality cost consists of present and future income lost as a result of early mortality from air pollution attributable illnesses. The attributable mortality cost $P A M C$ for each pollution subcategory $j$, from premature death by disease $i$ in the population subgroup $k$, is estimated as:

$$
P A M C_{j i k}=P A F_{j i k} \times \sum_{a=\min }^{\max }\left(D T H_{j i k a} \times P V L E_{k a}\right)
$$

where $P A F$ is the mean estimated value of the attributable to air pollution death fraction, $D T H$ is total number of deaths, $P V L E$ is the estimated present value of lifetime earnings and min - max are the minimum and maximum age groups, respectively.

To calculate the present value of lost productivity, that is, productivity that would have been achieved in future years had a person not died prematurely from air pollution attributable diseases, we use the formula by Max et al. (2004). Under this approach, we take into account life expectancy in the different five-year age groups in males and females, as well as labour force participation in each five-year age group and gender, respectively:

$$
P V L E_{a g}=\sum_{n=a}^{\max }\left(S P_{a g}(n)\right) \times\left[P R \times E M P_{g}(n)\right] \times \frac{(1+\mu)^{n-a}}{(1+r)^{n-a}}
$$

where $P V L E$ is the present value of lifetime earnings, $a$ is the present age of a person and $g$ its gender and $S P$ stands for survival probability. This survival probability can be interpreted as the probability that a person of gender $g$ which dies at age $a$ would have survived at age $n . P R$ is the chosen productivity measure, GDP per worker, $E M P_{g}(n)$ is the ratio of employment-to-population at gender $g$ and age $n, \mu$ is the growth rate of labour productivity and $r$ is the chosen discount rate. Regarding the annual labour productivity growth rate, we make the common assumption of 1 percent increase. We assume no discounting for human life. A sensitivity analysis is undertaken below assuming 3 percent discount rate.

The age groups included in the analysis are infants under 1 year of age (minimum) to $75-79$ years of age (maximum age group). We assume that no person above the age of 79 years is working. Defining the workforce in such a fashion could raise concerns of overestimation of indirect mortality cost. This is because not all people will start working from age 15 and many individuals will retire around the age of 65 (Narain and Sall, 2016). As already noted above, to account for this possible source of overestimation, indirect mortality cost (and morbidity cost below) is weighted by labour force participation, following the approach used by WB \& IHME (2016), discussed in Narain and Sall (2016, pp. 39-47).

Air pollution attributable indirect morbidity cost (PAIC) is calculated as:

$$
P A I C_{j i k}=P A F_{j i k} \times Y L D_{j i k} \times E M P_{k} \times P R
$$

where $P A F$ is the mean estimated value of air pollution attributable fraction of morbidity by air pollution subcategory $j$, disease $i$ and population subgroup $k$. YLD is the total number of Years Lived with Disability (YLD) by $j, i$ and $k$, $E M P$ is employment-to-population ratio by population subgroup $k$, and $P R$ is again GDP per worker.

The population subgroups included in the analysis are males and females of age 15-19 years to 75-79 years. As in the case of the estimation of indirect mortality cost, no person above the age of 79 years is assumed to be working. Unfortunately, the nature of the measure used to capture morbidity and the formula employed does not permit the estimation of morbidity cost in the age group of less than a year old up to 14 years old, a major difference compared to mortality cost estimation.

Finally, total economic cost of air-pollution attributable diseases TPAC by pollution subcategory $j$ is the sum of the direct and indirect morbidity and mortality costs:

$$
T P A C_{j}=P A E_{j}+P A M C_{j}+P A I C_{j}
$$

A frequent criticism of the COI methodology is that it underestimates the true cost of a disease in two ways. First, it yields low or no values for children and older people after the age of retirement. Second, it does not include 'psychological costs', in the sense that pain and suffering caused by a disease are not included in the indirect cost calculations (Max at al., 2004). In order to overcome these two shortcomings, the WTP approach has been proposed as an alternative method to valuing human life.

\subsection{Willingness to Pay Approach}

The origins of the WTP method date back in the late 1960s and early 1970s, when authors such as Schelling (1968) and Mishan (1971) suggested that valuing the prevention of premature mortality should be done through the amount that a person would be willing to pay for a decline in risk of early death (holding expected utility constant). Since then, the concept of WTP has gained an increasing importance in environmental decision-making and management, while WTP estimation for 'non-market-traded goods' has become a significant subfield of study in environmental economics (Baumgärtner et al., 2017). 
Formally, according to the WTP approach, life is valued through the monetary amount individuals are willing to pay for marginal reductions in their risk of dying from a given risk factor (OECD, 2012). Mortality cost of air pollution is calculated using the aggregate WTP or the VSL multiplied by the total number of premature deaths in a particular year. Since WTP surveys that provide information on the valuation of mortality risks associated with exposure to air pollution are not available for all countries, a set of OECD-recommend VSL values can be employed, adjusted for differences in income (OECD, 2012, 2014). The formula used for making the necessary adjustments for transferring the VSL is

$$
V S L_{2019}=V S L_{O E C D, 2005} \times\left(Y_{2005} / Y_{O E C D, 2005}\right)^{\beta} \times(1+\% \Delta P+\% \Delta Y)^{\beta}
$$

where $V S L_{2019}$ is the value of statistical life for Greece in 2019, VSL $L_{O E C D, 2005}$ is the VSL base value for the OECD countries (US\$ 3 million), $Y_{2005}$ is Greek GDP per capita at PPP in 2005, $Y_{O E C D, 2005}$ is the average GDP per capita of the OECD countries at PPP in $2005, \% \Delta P$ is the percentage change in consumer price and $\% \Delta Y$ is the percentage change in real GDP per capita growth from 2005 to 2019 . Finally, $\beta$ is the income elasticity of VSL.

\subsection{Data}

For the COI approach, we used the most recent data available (for 2019) on health effects of air pollution from the Global Burden of Disease 2019 study (GBD 2019, 2020), including attributable to air pollution fractions of death and disability (PAFs in formulae (1), (2) and (3)), as well as the total number of YLD (needed in formula (4)) and the total number of deaths (necessary in formula $(2)$ ).

THCE was retrieved from the IHME Global Expected Health Spending 2018-2050 dataset (2020). Age and gender specific employment-to-population ratios were obtained from the International Labour Organization (ILO) statistical database, as was the case with the total number of workers which we used in the calculation of the GDP per worker (ILO, 2020). Data on GDP were taken from the International Monetary Fund's (IMF) World Economic Outlook Database, October 2020 (IMF, 2020). Probabilities of survival were calculated using life tables available from the WHO (n.d.). All data concern the year 2019, except for life tables which are for 2016, the latest data available.

For the WTP approach, data for the necessary calculations were obtained by the World Bank's Word Development Indicators database (WB, 2020). The income elasticity of the VSL is assumed to be 0.8, following the OECD recommendation for transfers of the VSL between OECD (and EU) member countries (OECD, 2012). Formula (6) yields the VSL value for 2019 in $2005 \mathrm{US} \$$. This value is subsequently converted into local currency $(€)$, using the PPP-adjusted exchange rate (for private consumption, as proposed by OECD) for 2005 (OECD, 2012, p. 128). In order to convert the VSL from 2005 monetary value into 2019 monetary value, we used the national CPI for 2005 and 2019 (WB, 2020).

\section{Results}

\subsection{Cost-of-Illness Approach}

The share of healthcare expenditure due to air pollution attributable diseases in total healthcare expenditure was 4.8 percent in 2019. From this, 4.44 percent was due to ambient $\mathrm{PM}_{2.5}$ air pollution, 0.4 percent was due to ambient ozone pollution and 0.03 percent due to household $\mathrm{PM}_{2.5}$ air pollution related illnesses (see Table 1, at the end of this subsection).

Direct cost is estimated at $€ 742.16$ million. Direct cost due to ambient $\mathrm{PM}_{2.5}$ air pollution related illnesses comprised the largest share of the direct cost due to total air pollution, estimated to be $€ 682.11$ million, while healthcare expenditure due to ozone air pollution attributable diseases was estimated at €60.97 million. Direct cost due to exposure to household $\mathrm{PM}_{2.5}$ air pollution was $€ 4.91$ million, being by far the smallest component of direct cost due to exposure to total air pollution (see Table 1).

Turning to indirect cost, total morbidity cost was estimated at $€ 197.1$ million. From this, 99.2 percent was related to diseases attributed to ambient $\mathrm{PM}_{2.5}$ air pollution, while only 0.8 percent was due to household $\mathrm{PM}_{2.5}$ air pollution related illnesses. Morbidity cost accounted for 37.25 percent of the indirect cost of air pollution, while it was 15.5 percent of the total cost of air pollution. The economic cost of morbidity from air pollution is the smallest component of the total economic cost, while the largest component is by far the direct cost (see Table 1).

The distribution of morbidity cost from total air pollution, by age and gender, is depicted in Figure 1. The sharp decline of morbidity cost after the age of 59 years, and the particularly low estimates of morbidity cost for the 65-79 age group, are a result of the decreasing employment to population ratio. Morbidity cost resulting from males is higher than the one resulting from females in all age groups, except for the 25-29 age group. This is because both the number of YLD resulting from exposure to air pollution and participation in the labour market are higher in males than in females in all age groups, with the exception of the 25-29 age group, in which the number of YLD is higher for females. Figures A3 and A4 in Appendix A describe the age and gender distribution of morbidity cost from ambient and household $\mathrm{PM}_{2.5}$ air pollution, respectively. 
Figure 1. Morbidity cost from total air pollution by age and gender, Greece, 2019

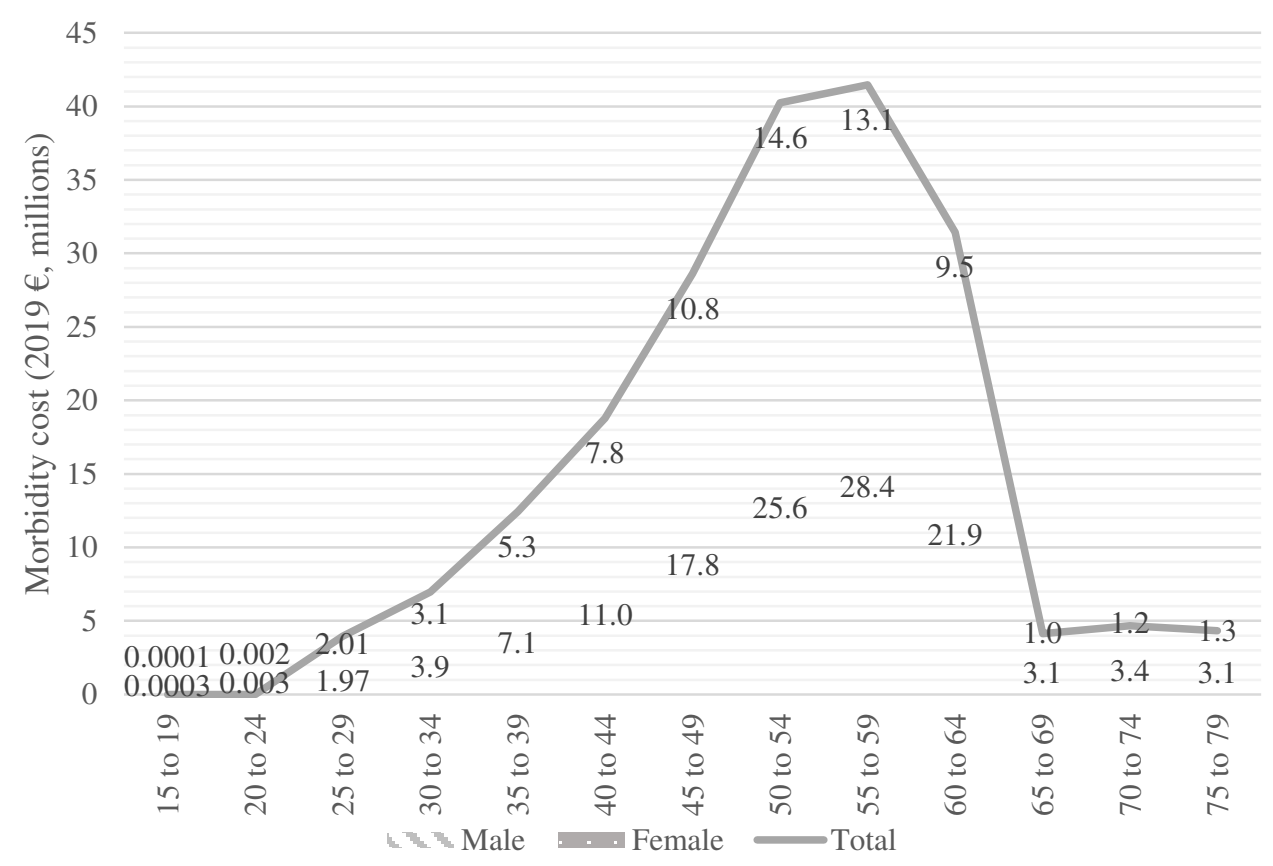

Sources: Own calculations based on data from the GBD 2019 (IHME), IMF and ILO

Mortality cost was estimated at $€ 331.9$ million in 2019 (Table 1). From this, 97.67 percent was due to ambient $\mathrm{PM}_{2.5}$ air pollution, 1.7 percent was due to ambient ozone pollution and only 0.63 percent resulted from exposure to household $\mathrm{PM}_{2.5}$ air pollution. The share of mortality cost in total cost was 26.1 percent, while the shares of direct and indirect morbidity cost were 58.4 percent and 15.5, respectively. The distribution of mortality cost from total air pollution, by age and gender, is presented in Figure 2. The distribution of mortality cost from each subcategory of air pollution, by age and gender, is presented in Figures A5-A7 in Appendix A.

Figure 2. Mortality cost from total air pollution by age and gender, Greece, 2019

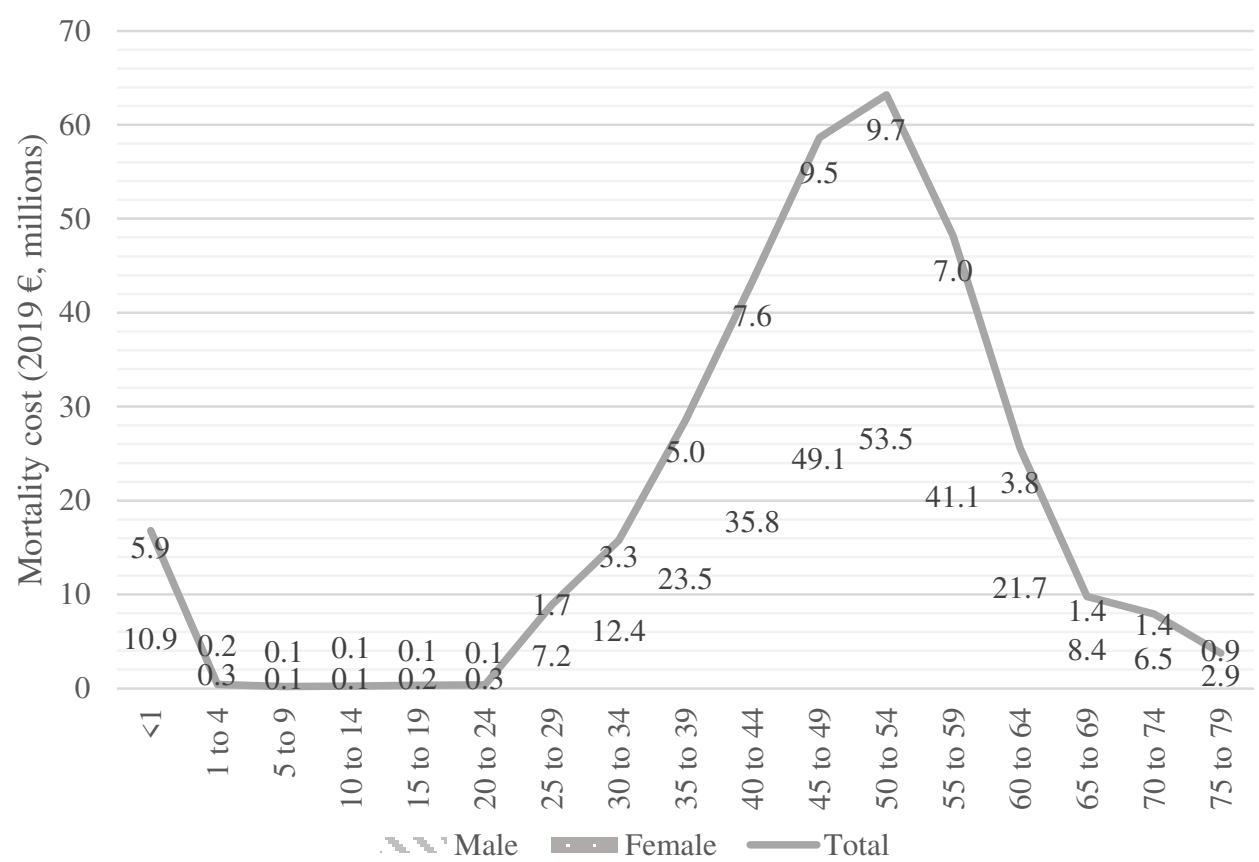

Sources: Own calculations based on data from the GBD 2019 (IHME), IMF and ILO

The highest proportion of mortality cost resulted from males in all age groups (see Figure 2 ). This is driven by the fact that the PVLE is higher for males than females in all age groups, but also by the fact that the health impact in terms of mortality is more severe in males than females in almost all age groups and from all air pollution subcategories. Noticeable exceptions are mortality estimates from exposure to ambient, household $\mathrm{PM}_{2.5}$ air pollution and the joint effects of all air pollutants in the age group 10-14, which are higher in females than in males. The same 
applies in the case of mortality from exposure to household $\mathrm{PM}_{2.5}$ air pollution in the 75-79 age group. Even in these cases, however, the relatively higher estimated PVLE in males results in higher mortality cost estimates for men.

Total cost resulting from exposure to air pollution was estimated at $€ 1.27$ billion in 2019 . From this, 94.1 percent was attributed to exposure to ambient $\mathrm{PM}_{2.5}$ air pollution and 5.2 percent to ambient ozone air pollution, while 0.7 percent resulted from household $\mathrm{PM}_{2.5}$ air pollution related diseases. The share of total cost from air pollution in GDP was 0.68 percent.

Assuming a 3 percent discount rate, mortality cost from total air pollution is estimated at €261.3 million (2019). That is, mortality cost due to exposure to air pollution is 21.3 percent lower, compared to 1 percent discount.

Table 1: Direct, indirect and total cost from air pollution, Greece, 2019

\begin{tabular}{|c|c|c|c|c|c|c|}
\hline & & Direct cost & \multicolumn{3}{|c|}{ Indirect cost } & \multirow[t]{2}{*}{ Total cost } \\
\hline & & & Morbidity & Mortality & Total & \\
\hline \multirow{6}{*}{$\begin{array}{l}\text { Total air } \\
\text { pollution }\end{array}$} & value $^{\mathrm{a}}$ & 742.16 & 197.1 & 331.9 & 529 & $1.27^{\mathrm{b}}$ \\
\hline & cost per capita ${ }^{c}$ & 69.25 & 18.4 & 31 & 49.4 & 118.65 \\
\hline & $\%$ GDP & 0.4 & 0.1 & 0.18 & 0.28 & 0.68 \\
\hline & $\%$ total cost & 58.4 & 15.5 & 26.1 & 41.6 & 100.0 \\
\hline & $\%$ indirect cost & - & 37.25 & 62.75 & 100.0 & - \\
\hline & \% health exp. & 4.8 & - & - & - & - \\
\hline \multirow{6}{*}{$\begin{array}{l}\text { Ambient } \\
\mathrm{PM}_{2.5}\end{array}$} & value $^{\mathrm{a}}$ & 682.11 & 195.5 & 324.7 & 520.2 & $1.2^{\mathrm{b}}$ \\
\hline & cost per capita ${ }^{c}$ & 63.65 & 18.25 & 30.3 & 48.55 & 112.2 \\
\hline & $\%$ GDP & 0.36 & 0.11 & 0.17 & 0.28 & 0.64 \\
\hline & $\%$ total cost & 56.7 & 16.3 & 27 & 43.3 & 100.0 \\
\hline & $\%$ indirect cost & - & 37.6 & 62.4 & 100.0 & - \\
\hline & \% health exp. & 4.44 & - & - & - & - \\
\hline \multirow{6}{*}{$\begin{array}{l}\text { Household } \\
\mathrm{PM}_{2.5}\end{array}$} & value $^{\mathrm{a}}$ & 4.91 & 1.57 & 2.1 & 3.67 & 8.58 \\
\hline & cost per capita ${ }^{c}$ & 0.46 & 0.15 & 0.2 & 0.35 & 0.8 \\
\hline & $\%$ GDP & 0.0026 & 0.0009 & 0.0011 & 0.002 & 0.0046 \\
\hline & $\%$ total cost & 57.25 & 18.35 & 24.4 & 42.75 & 100.0 \\
\hline & $\%$ indirect cost & - & 42.9 & 57.1 & 100.0 & - \\
\hline & \% health exp. & 0.03 & - & - & - & - \\
\hline \multirow{6}{*}{$\begin{array}{l}\text { Ambient } \\
\text { ozone }\end{array}$} & value $^{\mathrm{a}}$ & 60.97 & - & 5.63 & 5.63 & 66.6 \\
\hline & cost per capitac & 5.7 & - & 0.5 & 0.5 & 6.2 \\
\hline & $\%$ GDP & 0.033 & - & 0.003 & 0.003 & 0.036 \\
\hline & $\%$ total cost & 91.55 & - & 8.45 & 8.45 & 100.0 \\
\hline & $\%$ indirect cost & - & - & 100.0 & 100.0 & - \\
\hline & \% health exp. & 0.4 & - & - & - & - \\
\hline
\end{tabular}

Note: The sum of estimated costs and cost shares in GDP related to ambient, household $\mathrm{PM}_{2.5}$ and ambient ozone air pollution are slightly higher than estimates corresponding to total air pollution, reflecting the structure of the health data used. Costs reported for individual air pollution risk factors quantify the economic impact of each subcategory separately, while those reported for total air pollution signify joint effects.

Source: Own calculations based on data from the GBD 2019 (IHME), IMF and ILO

a Monetary amount in 2019, $2019 €$, millions

b Monetary amount in $2019,2019 €$, billions

c Monetary amount in $2019,2019 €$

\subsection{The Willingness to Pay Approach}

Using formula (5), the VSL for Greece in 2019 is

$$
V S L_{\text {Greece,2019 }}=(\text { US\$ } 3 \text { million }) \times(0.86)^{0.8} \times(1+0.195+(-0.154))^{0.8}=2.75
$$

That is, the VSL is US\$ 2.75 million measured in 2005 PPP-adjusted. When converting this monetary value into local currency, the VSL value becomes $€ 2.08$ million (in 2005 terms). Finally, we convert the VSL to 2019 national monetary value, which is $€ 2.49$ million.

By multiplying this VSL value with the total number of deaths resulting from exposure to air pollution, mortality cost was estimated at $€ 6.48$ billion in 2019 or, equivalently, 3.46 percent of GDP. As expected, the estimate using the WTP approach is significantly higher than the one obtained under the COI approach, as the former represents welfare losses due to premature mortality from air pollution attributable diseases, while the latter concerns only market losses due to forgone income from early mortality resulting from exposure to air pollution.

The WTP approach is a methodology suitable for calculating the welfare cost from reduced air quality and the associated mortality outcome in the society as a whole, including the 80 years and above group of age. In this case, the economic cost of mortality from total air pollution becomes even higher, as it is estimated at €15.47 billion, or 8.25 percent of GDP. This result was, of course, expected, since the number of deaths attributable to air pollution related diseases skyrockets in the age group of 80 years and above (Figure A2 in Appendix A).

For a sensitivity analysis using alternative income elasticities of the VSL, that is, income elasticities of 0.4 (proposed by OECD (2012)), o.6 and 1.0 (following the WB and IHME (2016) work), see Table A1, in Appendix A. 


\section{Discussion}

Our findings, based on the COI approach, indicate that air pollution attributable diseases resulted in a total economic cost of $€ 1.27$ billion in 2019 , or equivalently to 0.68 percent of GDP. From this cost, $€ 742.16$ million (0.4 percent of GDP) is related to healthcare expenditure due to air pollution related diseases, €331.9 million (0.18 percent of GDP) results from premature mortality, and $€ 197.1$ million (0.1 percent of GDP) is due to morbidity from exposure to air pollution.

To estimate morbidity cost, we took into account the number of YLD from all health conditions resulting from exposure to ambient, household $\mathrm{PM}_{2.5}$ and ambient ozone air pollution, as estimated by IHME. The EC Impact Assessment (EC, 2013) bases morbidity cost estimates on the number of lost working days resulting mainly from respiratory conditions from ambient particulate matter and ambient ozone air pollution, while household air pollution is not taken into account. Moreover, healthcare cost is calculated through the number of respiratory and cardiovascular hospital admissions as well as the cases of chronic bronchitis, while in the present analysis data on all specific-cause health outcomes were taken into account. It should be noted, however, that our calculation of direct cost was conducted through air pollution attributable fractions which were based on premature mortality estimates and, therefore, healthcare expenditure due to air pollution may be either underestimated or overestimated.

When it comes to mortality cost estimation, our analysis (under the COI method) is closer to the WB \& IHME (2016) report. However, the assumptions regarding the growth rate of labour productivity and the discount rate differ, and the PVLEs are calculated in a slightly different way. While mortality cost estimates are close to, but higher than, the ones offered by the WB \& IHME (2016) study, our overall estimate of total economic cost accounts for almost 0.7 percent of GDP.

By analysing all relevant cost components resulting from the health impact of air pollution, it becomes more than clear that indirect morbidity cost and healthcare expenditure due to air pollution should not be overlooked in relevant international research. Direct cost due to total air pollution was found to be the component with the largest share in total cost (58.4 percent) followed by indirect mortality cost (26.1 percent). At the same time, the share of morbidity cost in indirect cost resulting from the joint effects of all air pollutants under examination was 37.25 percent. From the air pollution subcategories under examination, ambient $\mathrm{PM}_{2.5}$ air pollution was by far the most significant contributor to total economic cost.

In terms of limitations present when employing the COI method, one of the most common criticisms relates to the valuation of human life, which is done through the estimation of PVLE in the case of mortality and forgone income due to disability. This means that people that do not participate in the labour market (e.g., older people after the age of retirement) are excluded from the analysis (Max et al., 2004, pp. 7-8). This is more important when examining the economic cost of the burden of disease from air pollution exposure, compared to other risk factors commonly studied in the literature, since the health effects due to air pollution are particularly high for old people (see Appendix A). We calculated the economic cost of air pollution-related diseases for a wider range of age groups $(<1-79$ years of age) than in similar analyses (e.g., <1-65 years of age) but, nevertheless, people over the age of 80 years were excluded, as it was assumed that no person in this age group is participating in the labour market. Moreover, for the age group of 65-79 years, the resulting economic cost was low (compared to younger age groups) due to its low participation rate in the labour market (and despite the fact that mortality and morbidity estimates were high compared to younger ages). As a result, these shortcomings bring about an underestimate of the economic cost of the health effects from air pollution exposure.

Under a welfare-based approach (WTP), mortality cost due to exposure to air pollution was found to be even higher and equal to 3.46 percent of GDP, when mortality estimates in the age group under 1 year and up to 79 years old are taken into account. This welfare cost accounts for 8.25 percent of GDP, when mortality estimates for the whole population, including the age group of 80 years and above, are provided. These estimates are obtained using the OECD-recommended (2012; 2014) base VSL, a common practice especially among OECD and EU member countries due to the lack of primary WTP surveys. Note, however, that WTP depends heavily on income, inequality of income distribution and other socio-economic characteristics related to a specific context (Baumgärtner et al., 2017). This means that, if a primary WTP survey were to be conducted in Greece, a different VSL could possibly be uncovered, leading to a different welfare cost estimate of the impact of air pollution on health. Despite the fact that in our calculations we have made all the necessary adjustments with respect to income, inflation and income growth, the lack of WTP surveys covering the whole country is a potential shortcoming. Investigating this issue further presents research opportunities for the future.

Finally, under both cost estimation methods, data unavailability prevented the examination of the economic cost resulting from the burden of disease due to exposure to other air pollutants causing negative health effects, such as Nitrogen Dioxide (NO2) and Sulphur Dioxide.

\section{Policy implications and conclusion}

Offering incentives for the use of alternative energy fuels by households could lead to a reduction in $\mathrm{PM}_{2.5}$ air pollution concentrations and the attributable health impact. Despite the decreasing trend in the reported ambient $\mathrm{PM}_{2.5}$ air pollution concentrations recorded over the last years in Greece, there is room for further abatement efforts in major sectors, such as industrial processes and transportation. In the period 2010 to 2018 , the largest amount of $\mathrm{PM}_{2.5}$ air pollution emissions resulted from households (EEA, 2020). Among others, wood and solid fuels combustion 
for heat generation has been an activity that greatly contributed to the problem of reduced air quality, with available data pertaining not only to the case of Greece but also to other parts of the European continent (EEA, 2019).

Environmental incentives should be examined under a CB approach. Offering an incentive for the use of natural gas, instead of wood/biomass as a heating fuel, would require a lower environmental tax on the former, leading to reduced revenue from this source. On the other hand, lower $\mathrm{PM}_{2.5}$ air pollution concentrations would lead to a reduction in the economic cost resulting from diseases attributed to this risk-factor. The matter is complicated even further, if we take into account that, despite the negative impact on human health, biomass is considered a renewable and carbon-neutral source of energy and, generally speaking, its burning for heating purposes is promoted under energy and climate policies (Banja et al., 2020). Therefore, within a market-based framework, all relevant costs and benefits should be taken into account. This means that collaboration of different governmental agencies is important for improvements in both public health and the public budget.

In the context of energy transition and for meeting the EU 2030 energy and climate targets, Greece has decided to progressively phase out lignite-fired power generation and completely cease the use of coal/lignite in electricity production by 2028 (Hellenic Ministry of Environment and Energy (HMEE), 2019). An ambitious target has also been set regarding the share of renewable energy sources (RES) in electricity consumption, with a provision for this share to exceed 60 percent (HMEE, 2019, p.5). If this target is met, not only the health impact and the associated economic cost of ambient $\mathrm{PM}_{2.5}$ air pollution concentrations will decrease (especially in the regions in which lignite power plants were located), but also greenhouse gas emissions will fall significantly. This way, the transition into a 'climate neutral' economy will be facilitated and Greece will contribute to global efforts in mitigating the effects of climate change. It is worth mentioning, however, that if an increased penetration of RES in electricity generation is not achieved finally, the substitution of lignite with other non-renewable sources, such as natural gas, will have a less profound impact on abatement targets regarding greenhouse gas emissions.

The "zero pollution action plan" (EC, COM (2021) 400 final) provides opportunities for further action. For climate neutrality to be achieved by 2050 , all EU relevant laws, policies and initiatives should include key targets of pollution reduction and prevention, adopted and implemented by 2030. One of the most noteworthy targets, in the context of our analysis, is the goal of reducing premature mortality due to air pollution exposure by more than 55 percent. To this end, it is recognized that air quality standards set by the EU are less stringent than the WHO air quality guidelines (WHO, 2006) and the EU Ambient Air Quality Directives should be revised to be more closely aligned with the WHO recommendations. This is expected to happen in 2022. Taking into account both our market and welfare cost estimates, significant cost savings are expected to be realized, provided Greece takes action in a timely fashion and achieves the health-related target by 2030. An issue of concern, however, is the frequent delays in the transposition and implementation of EU environmental legislation. It is only recently that Greece's National Air Pollution Control Programme (obligatory under the Directive (EU) 2016/2284, with a submission deadline by April 1 2019) has been adopted (January 2021).

Energy related restructuring, from the reduction of fossil fuels-based electricity generation to the de-carbonization of energy consumption patterns in households and transport, can lead to significant co-benefits in the fields of climate change mitigation and protection of human health. The synergies that would result, if appropriate policy measures were to be designed and implemented, can be important. For example, Nitrogen Oxides and especially $\mathrm{NO} 2$ concentration limit target values set by the EU should be met in the major Greek metropolitan areas. Nitrogen Oxides are harmful for human health by themselves, but they are also important precursors of ground-level ozone air pollution.

These policy considerations are relevant not only for the case of Greece, since they can also serve as a guide to other economies with similar structural characteristics and comparable levels of exposure to air pollution. Data from the OECD environment at a glance indicators platform, for example, reveal that mean annual exposure of the population to $\mathrm{PM}_{2.5}$ in Greece is slightly higher than the OECD average (in 2019) (OECD, 2020). Despite improvements in air quality in advanced economies, air pollution abatement efforts should continue. The end goal should be a reduction in exposure to harmful air pollutants and consequently a decrease in air-pollution related health effects, which would, ultimately, lead to a reduced market and welfare cost.

The need for limiting emissions/concentrations of air pollutants and the negative externalities associated with their adverse effects on public health is an issue that concerns all people irrespective of age, gender and income in all countries (Health Effects Institute, 2019). Recent evidence has indicated that long-term air pollution exposure increases the susceptibility of the affected population to other risk factors affecting human health, such as the COVID19 disease (Pozzer et al., 2020; Wu et al., 2020). Given the budgetary resources necessary for fighting the challenges of the healthcare systems during the ongoing pandemic, and the welfare costs associated with the loss of human life and the consequences of the COVID-19 health crisis for the economy, future policy measures should concentrate (among other things) on limiting the negative impact of air pollution on public health. Reduced air quality can be a potentially important cofounding factor leading to premature mortality from infectious respiratory diseases. Investing in clean air can be a policy priority with clear long-term benefits. Apart from current cost savings in terms of direct and indirect (mortality and morbidity) costs, enhanced air quality can lead to improved public health, which can be seen as a preventive action designed to mitigate harm in the event of a pandemic.

Taking into account that epidemiological research is advancing in documenting the adverse effects on human health form exposure to various other air pollutants (not included here) and that more health conditions are currently being associated with exposure to air pollution, economic cost estimates of the burden of disease from this risk factor are expected to be revised upwards in the near future. 
Alberini, A., Krupnick, A., 2000, Cost-of-Illness and Willingness-to-Pay Estimates of the Benefits of Improved Air Quality: Evidence from Taiwan, Land Economics, 76(1), pp. 37-53, https://doi.org/10.2307/3147256

Aşici, A., Bünül, Z., 2012, Green new deal: a green way out of the crisis? Environmental Policy Governance, 22(5), pp. 295-306, $\underline{\text { https://doi.org/10.1002/eet.1594 }}$

Banja, M., Đukanović, G., Belis, C.A., 2020, Status of Air Pollutants and Greenhouse Gases in the Western Balkans: Benchmarking the Accession Process on Environment. EUR 301113 EN. Publications Office of the European Union, Luxembourg, viewed 15 December

https://publications.jrc.ec.europa.eu/repository/bitstream/JRC118679/air_qualityghg_western_balkans_online.pdf

Baumgärtner, S., Drupp, M.A., Meya, J.N., Munz, J.M., Quaas, M.F., 2017, Income inequality and willingness to pay for environmental public goods, Journal of Environmental Economics and Management, 85, pp. 35-61, https://doi.org/10.1016/j.jeem.2017.04.005

Bherwani, H., Nair, M., Musugu, K., Gautam, S., Gupta, A., Kapley, A., Rakesh, K., 2020, Valuation of air pollution externalities: comparative assessment of economic damage and emission reduction under COVID-19 lockdown, Air Quality, Atmosphere \& Health, 13, pp. 683-694, https://doi.org/10.1007/s11869-020-00845-3

Burnett, R., et al., 2018, Global estimates of mortality associated with long-term exposure to outdoor fine particulate matter, Proc Natl Acad Sci U S A, $115(38)$, pp. 9592-9597, https://doi.org/10.1073/pnas.1803222115

Croitoru, L., Cervigni, R., Jabarin, A., 2010, Air Pollution: The Case of Jordan, In: Croitoru, L., and Sarraf, M. ed. The Cost of Environmental Degradation: Case Studies from the Middle East and North Africa, Washington, D.C.: World Bank, pp. 37-52

Cropper, M.L., 2000, Has Economic Research Answered the Needs of Environmental Policy? Journal of Environmental Economics and Management, 39(3), pp. 325-350, https://doi.org/10.1006/jeem.2000.1128

Custers, P., 2010, The tasks of Keynesianism today: green new deals as transition towards a zero growth economy? New Political Science, 32(2), pp. 173-191, https://doi.org/10.1080/07393141003722032

European Commission (EC), n.d., Air Quality Standards, viewed $25 \quad$ January 2021 ,

EC, 2007, State of European Cities Report: Adding Value to the European Urban Audit, viewed 10 January 2021 , https://ec.europa.eu/regional_policy/sources/docgener/studies/pdf/urban/stateofcities_2007.pdf

EC, 2013, Impact Assessment - accompanying the documents \{COM(2013)917\} \{COM(2013)918\} \{COM(2013)919\} $\{\operatorname{COM}(2013) 920\}\{\operatorname{SWD}(2013) 532\}$. Commission Staff Working Document, SWD (2013) 531 final.

EC, 2021, EU Action Plan: 'Towards Zero Pollution for Air, Water and Soil, COM(2021) 400 final, https://eurlex.europa.eu/legal-content/EN/TXT/?uri=CELEX:52021DCO400

European Environmental Agency (EEA), 2008, Air Pollution in Athens: Existing Status and Abatement Practices, viewed 30 January 2021. https://www.eea.europa.eu/publications/2599XXX/page018.html

EEA, 2011, Revealing the Costs of Air Pollution from Industrial Facilities in Europe, (EEA Technical Report No. 15/2011), Publications Office of the European Union, Luxembourg, viewed 10 December 2020, https://www.eea.europa.eu/publications/cost-of-airpollution

EEA, 2019, The European Environment - State and Outlook 2020: Knowledge for Transition to a Sustainable Europe. Publications Office of the European Union, Luxembourg, viewed 15 February 2021, https://www.eea.europa.eu/publications/soer-2020

EEA, 2020, Greece - Air Pollution Country Fact Sheet 2020, viewed 1 February 2021, https:// www.eea.europa.eu/themes/air/country-fact-sheets/2020-country-fact-sheets/greece

Galvin R., Healy, N., 2020, The Green New Deal in the United States: What it is and how to pay for it, Energy Research E̊ Social Science, 67, https://doi.org/10.1016/j.erss.2020.101529

Georgakellos, A.D., 2007, External cost of air pollution from thermal power plants: case of Greece, International Journal of Energy Sector Management, 1(3), pp. 257-272, https://doi.org/10.1108/17506220710821134

Global Burden of Disease Collaborative Network, 2020, Global Burden of Disease Study 2019 (GBD 2019) Results. Institute for Health Metrics and Evaluation (IHME), viewed 10 November 2020, http://ghdx.healthdata.org/gbd-results-tool

Global Burden of Disease Collaborative Network, 2020, Global Expected Health Spending 2018-2050 (Data set). Institutive for Health Metrics and Evaluation (IHME), viewed 10 November 2020, https://doi.org/10.6069/oPWC-PV84

Harris, J.M., 2019, Ecological Economics of the Green New Deal, Global Development And Environment Institute (GDAE),

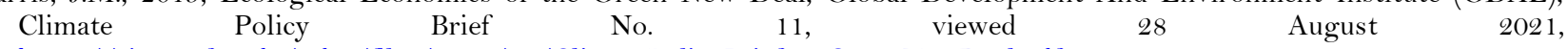
https://sites.tufts.edu/gdae/files/2019/10/ClimatePolicyBrief11_GreenNewDeal.pdf

Health Effects Institute, 2019, State of Global Air 2019. Special Report. Health Effects Institute, Boston, MA, viewed 20 December 2020, https://www.stateofglobalair.org/sites/default/files/soga_2019_report.pdf

Hellenic Ministry of Environment and Energy (HMEE), 2019, National Energy and Climate Plan (NECP), viewed 6 February 2021 , https://ec.europa.eu/energy/sites/ener/files/el_final_necp_main_en.pdf

International Labour Organization (ILO), 2020, Labour Force statistics: Employment-to-population ratio by sex and age (Data set), ILOSTAT, viewed 15 November 2020, https://ilostat.ilo.org/data/

ILO, 2020, ILO modelled estimates and projections: Employment by sex and age, Nov. 2019 (thousands) (Data set), ILOSTAT, viewed 15 November 2020, https://ilostat.ilo.org/data/

International Monetary Fund (IMF), 2020, World Economic Outlook Database, October 2020, viewed 12 December 2020 , https://www.imf.org/en/Publications/WEO/weo-database/2020/October/

Jo, C., 2014, Cost-of-illness studies: concepts, scopes, and methods, Clin Mol Hepatol, 20(4), pp. 327-337, https://doi.org/10.3350/cmh.2014.20.4.327

Landrigan, P., et al., 2018, The Lancet Commission on pollution and health, Lancet, 391, pp.462-512, https://doi.org/10.1016/So140-6736(17)32345-0

Lelieveld, J., Klingmüller, K., Pozzer, A., Pöschl, U., Fnais, M., Daiber, A., Münzel, T., 2019, Cardiovascular disease burden from ambient air pollution in Europe reassessed using novel hazard ratio functions. European Heart Journal, 40(20), pp. $1590-1596$ 
Lindhjem, H., Navrud, S., Braathen, N.A., Biausque, V., 2011, Valuing Mortality Risk Reductions from Environmental, Transport, and Health Policies: A Global Meta-Analysis of Stated Preference Studies, Risk Analysis, 31(3), pp. 1381-407, https://doi.org/10.1111/j.1539-6924.2011.01694.x

Lu, X., Yao, T., Fung, J.C.H., Lin, C., 2016, Estimation of health and economic costs of air pollution over the Pearl River Delta region in China, Science of The Total Environment, 566-567, pp. 134-143, https://doi.org/10.1016/j.scitotenv.2016.05.060

Luke, T., 2009, A green new deal: why green, how new, and what is the deal? Critical Policy Studies, 3(1), pp. 14-28, https://doi.org/10.1080/19460170903158065

Martinez, G.S., Spadaro, J.V., Chapizanis, D., Kendrovski, V., Kochubovski, M., Mudu, P., 2018, Health Impacts and Economic Costs of Air Pollution in the Metropolitan Area of Skopje, International Journal of Environmental Research and Public Health, 15(4), pp. 626, https://doi.org/10.3390/ijerph15040626

Max, W., Rice, D., Sung, H., Michel, M., 2004, Valuing Human Life: Estimating the Present Value of Lifetime Earnings, 2000, https://escholarship.org/uc/item/82d0550k

Mazzucato, M., 2020, Covid-19 and the Green New Deal, United Nations Department of Economic and Social Affairs (UNDESA), 25(12), viewed 28 August 2021, https://www.un.org/development/desa/undesavoice/more-fromundesa/2020/12/50538.html

Mazzucato, M., McPherson, M., 2018, The Green New Deal: A bold mission-oriented approach, UCL Institute for Innovation and Public Purpose (IIPP), Policy Brief Series (IIPP PB 04), viewed 28 August 2021, https://www.ucl.ac.uk/bartlett/publicpurpose/publications/2018/dec/green-new-deal-bold-mission-oriented-approach

Meisner, C., Gjorgjev, D., Tozija, F., 2015, Estimating health impacts and economic costs of air pollution in the Republic of Macedonia (Original research). South Eastern European Journal of Public Health, IV, https://doi.org/10.4119/seejph-1809

Mirasgedis, S., Hontou, V., Georgopoulou, E., Sarafidis, Y., Gakis, N., Lalas, D.P., Loukatos, A., Gargoulas, N., Mentzis, A., Economidis, D., Triantafilopoulos, T., Korizi, K., Mavrotas, G., 2008, Environmental Damage Costs from Airborne Pollution of Industrial Activities in the Greater Athens, Greece Area and the Resulting Benefits from the Introduction of BAT. Environmental Impact Assessment Review, 28(1), pp. 39-56, https://doi.org/10.1016/j.eiar.2007.03.006

Mishan, E.J., 1971, Evaluation of Life and Limb: A Theoretical Approach, Journal of Political Economy, 79(4), pp. 687-705

Narain, U., Sall, C., 2016, Methodology for Valuing the Health Impacts of Air Pollution: Discussion of Challenges and Proposed Solutions (English). World Bank Group, viewed 8 November http://documents.worldbank.org/curated/en/832 141466999681767/Methodology-for-valuing-the-health-impacts-of-airpollution-discussion-of-challenges-and-proposed-solutions

National Centre for the Environment and Sustainable Development (NCESD), 2018, Greece: State of the Environment Report, Summary/2018, viewed 2 January 2021, https://ekpaa.ypeka.gr/wp-content/uploads/2019/10/Greece-State-of-theEnvironment-Report-Summary-2018-English-Version_WEB.pdf

Organisation for Economic Cooperation and Development (OECD), 2009, OECD Environmental Performance Reviews: Greece 2009, viewed 30 January 2021 , https://dx.doi.org/10.1787/9789264061330-en

OECD, 2012, Mortality Risk in Environment, Health and Transport Policies, OECD Publishing, Paris, http://dx.doi.org/10.1787/9789264130807-en

OECD, 2014, The Cost of Air Pollution: Health Impacts of Road Transport, OECD Publishing, Paris, http://dx.doi.org/10.1787/9789264210488-en

OECD, 2016, The Economic Consequences of Outdoor Air Pollution, OECD Publishing, Paris, https://doi.org/10.1787/9789264257474-en

OECD, 2020, Environment at a Glance Indicators: Air quality, viewed 30 January 2021, https://www.oecdilibrary.org/sites/80661e2d-en/index.html?itemId=/content/component/80661e2d-en\#section-d 1e2181

Patankar, A.M., Trivedi, P.L., 2011 , Monetary burden of health impacts of air pollution in Mumbai, India: Implications for public health policy, Public Health, 125(3), pp. 157-164, https://doi.org/10.1016/i.puhe.2010.11.009

Pozzer, A., Dominici, F., Haines, A., Witt, C., Münzel, T., Levieveld, J., 2020, Regional and global contributions of air pollution to risk of death from COVID-19. Cardiovascular Research, 116(14), pp. 2247-2253, https://doi.org/10.1093/cvr/cvaa288

Rice, D., 1967, Estimating the Cost of Illness, American Journal of Public Health, 57(3), pp. 424-440, https://doi.org/10.2105/AJPH.57.3.424

Rice, D., Hodgson, T., Kopstein, A., 1985, The economic cost of illness: a replication and update. Health Care Finance Rev, 7(1), pp. 61-80, PMID: 1031139

Sander, K., Mira-Salama, D., Feuerbacher, A., 2015, The Cost of Air Pollution: A Case Study for the City of Cuenca, Ecuador, Washington, D.C.: World Bank, https://openknowledge.worldbank.org/handle/10986/22579

Sarigiannis, A.D., Karakitsios, S.P., Kermenidou, M.V., 2015, Health Impact and Monetary Cost of Exposure to Particulate Matter Emitted from Biomass Burning in Large Cities. Science of the Total Environment, 15(524-525), pp. 319-330, https://doi.org/10.1016/j.scitotenv.2015.02.108

Schelling, T.C., 1968, The life you save may be your own, In: Chase S.B. Jr. ed. Problems in Public Expenditure Analysis, Washington, D.C.: The Brookings Institution

Tarricone, R., 2006, Cost-of-illness analysis: What room in health economics? Health Policy, 77(1), pp. 51-63, https://doi.org/10.1016/j.healthpol.2005.07.016

Viscusi, W.K., Aldy, J.E., 2003, The Value of a Statistical Life: A Critical Review of Market Estimates Throughout the World, Journal of Risk and Uncertainty, 27(1), pp. 5-76, https://doi.org/10.1023/A:1025598106257

Viscusi, W.K., 2010, The heterogeneity of the value of statistical life: Introduction and overview, Journal of Risk and Uncertainty, 40(1), pp. 1-13, https://doi.org/10.1007/s11166-009-9083-Z

Vlachokostas, C., Achillas, C., Slini. T., Moussiopoulos, N., Banias, G., Dimitrakis, I., 2011, Willingness to pay for reducing the risk of premature mortality attributed to air pollution: a contingent valuation study for Greece, Atmospheric Pollution Research, 2(3), pp. 275-282, https://doi.org/10.5094/APR.2011.034

Vlachokostas, C., Achillas, C., Moussiopoulos, N., 2012, Health effects and social costs of particulate and photochemical urban air pollution: a case study for Thessaloniki, Greece. Air Quality Atmosphere $\Xi^{\circ}$ Health, 5(3), pp. 325-334, https://doi.org/10.1007/s11869-010-0096-1

White, D., 2019, Just Transitions/Design for Transitions: Preliminary Notes on a Design Politics for a Green New Deal, Capitalism Nature Socialism, 31 (2) pp. 20-39, https://doi.org/10.1080/10455752.2019.1583762 
World Bank (WB) and Institute for Health Metrics and Evaluation (IHME), 2016, The Cost of Air Pollution: Strengthening the Economic Case for Action, World Bank, Washington, DC, viewed 30 October 2020, https://openknowledge.worldbank.org/handle/10986/25013

WB, 2021, World Development Indicators (Data set), viewed 10 May 2021, https://databank.worldbank.org/source/world-development-indicators

World Health Organization (WHO), n.d., Air pollution, viewed 20 August 2021, https://www.who.int/healthtopics/air-pollution

WHO Regional Office for Europe, 2006, Air Quality Guidelines: Global Update 2005, viewed 28 January 2021 , https://www.euro.who.int/_data/assets/pdf_file/0005/78638/E90038.pdf

WHO Regional Office for Europe \& Organisation for Economic Co-operation and Development (OECD), 2015, Economic cost of the health impact of air pollution in Europe: Clean air, health and wealth, WHO Regional Office for Europe, Copenhagen, viewed $\quad 15 \quad$ November https://www.euro.who.int/_data/assets/pdf_file/0004/276772/Economic-cost-health-impact-air-pollutionen.pdf?ua $=1$

WHO, n.d., Global Health Observatory data repository: Life tables by country (Data set), viewed 23 October 2020 , https://apps.who.int/gho/data/node.main.687?lang=en

Wu. X., Nethery, R.C., Sabath, M.B., Braun, D., Dominici, F., 2020, Air pollution and COVID-19 mortality in the United States: Strengths and limitations of an ecological regression analysis. Science Advances, 6(45), pp. 1-6, https://doi.org/10.1126/sciadv.abd4049

Appendix A

Table A1: Greece-specific VSL value \& mortality cost from air pollution, 2019

\begin{tabular}{|c|c|c|c|}
\hline & $\begin{array}{l}\text { Income elasticity of VSL } \\
\text { of } 0.4\end{array}$ & $\begin{array}{l}\text { Income elasticity of VSL } \\
\text { of } 0.6\end{array}$ & $\begin{array}{l}\text { Income elasticity of VSL } \\
\text { of } 1.0\end{array}$ \\
\hline $\begin{array}{l}\text { OECD VSL base value } \\
(2005) \text { US } \$ \text {, millions, } \\
\text { PPP-adjusted }\end{array}$ & 3.00 & 3.00 & 3.00 \\
\hline $\begin{array}{l}\text { Country-specific VSL } \\
(2019) \text { in } 2005 \mathrm{US} \$ \text {, } \\
\text { millions, PPP-adjusted }\end{array}$ & 2.87 & 2.81 & 2.69 \\
\hline $\begin{array}{l}\text { Country-specific } \\
(2019) \text { in } 2019 \quad €, \\
\text { millions }^{1}\end{array}$ & 2.6 & 2.54 & 2.43 \\
\hline $\begin{array}{l}\text { Mortality cost (2019) in } \\
2019 € \text {, billions, ages }<1 \\
\text { to } 79\end{array}$ & 6.78 & 6.63 & 6.34 \\
\hline $\begin{array}{l}\text { Mortality cost \% GDP, } \\
\text { ages }<1 \text { to } 79\end{array}$ & 3.62 & 3.54 & 3.38 \\
\hline $\begin{array}{l}\text { Mortality cost (2019) in } \\
2019 € \text {, billions, all ages }\end{array}$ & 16.17 & 15.82 & 15.13 \\
\hline $\begin{array}{l}\text { Mortality cost \% GDP, } \\
\text { all ages }\end{array}$ & 8.63 & 8.44 & 8.07 \\
\hline
\end{tabular}

${ }^{1}$ Calculated using the OECD base value of US\$ 3 million (PPP-adjusted) in 2005, with adjustments being made with respect to differences in per capita income, post-2005 income growth and inflation. The income elasticities of the VSL employed are 0.4, 0.6 and 1.0, respectively, following the recommendations of OECD (2012) and the work of WB - IHME (2016) as described in the technical report by Narain and Sall (2016).

Source: Own calculations based on data from the GBD 2019 (IHME), OECD and the World Bank 
Figure A1. Number of Years lived with Disability and number of deaths from air pollution by gender, Greece, 2019

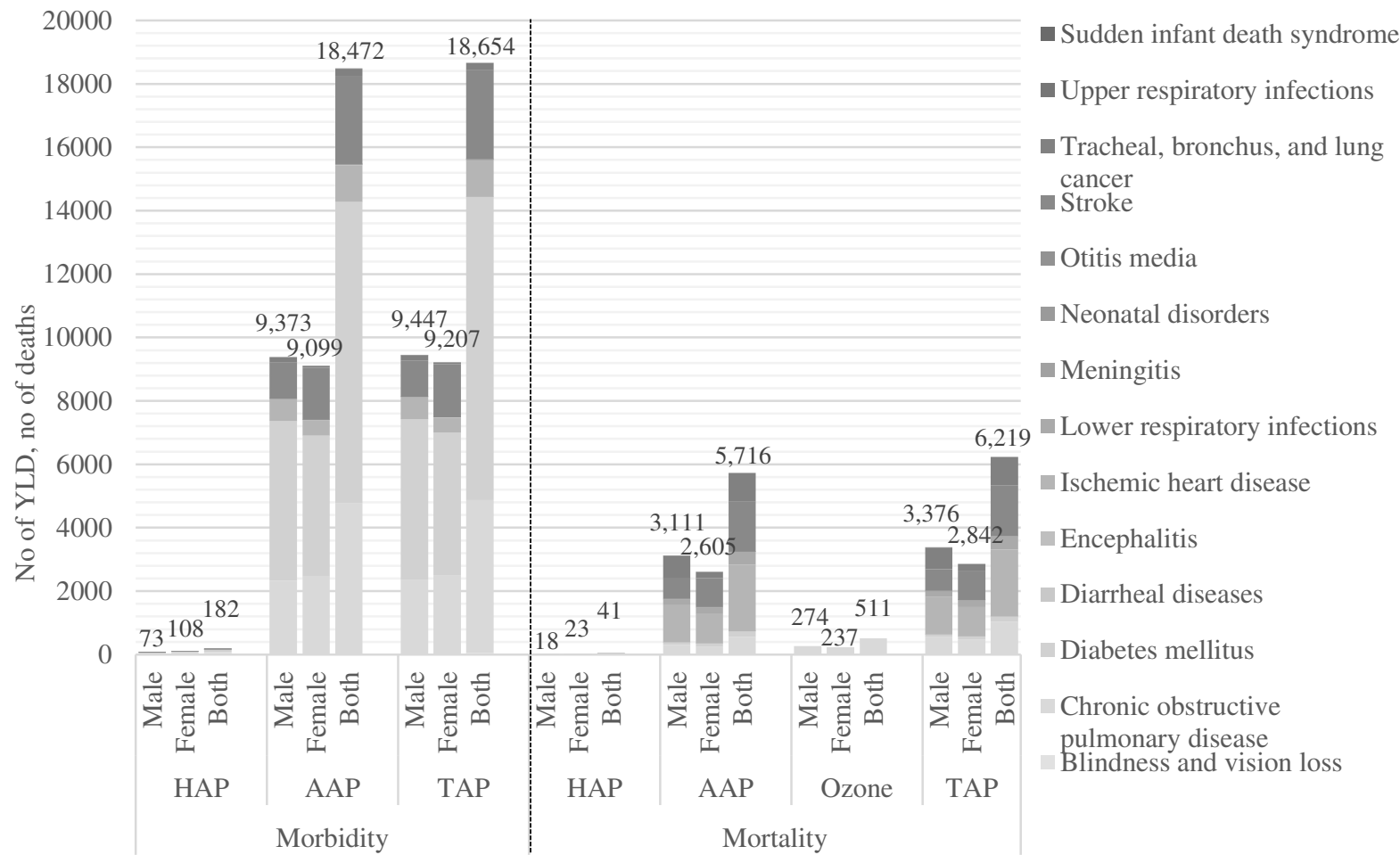

Source: Based on data from the GBD 2019 (IHME)

Figure A2. Number of Years lived with Disability and number of deaths from air pollution by age, Greece, 2019

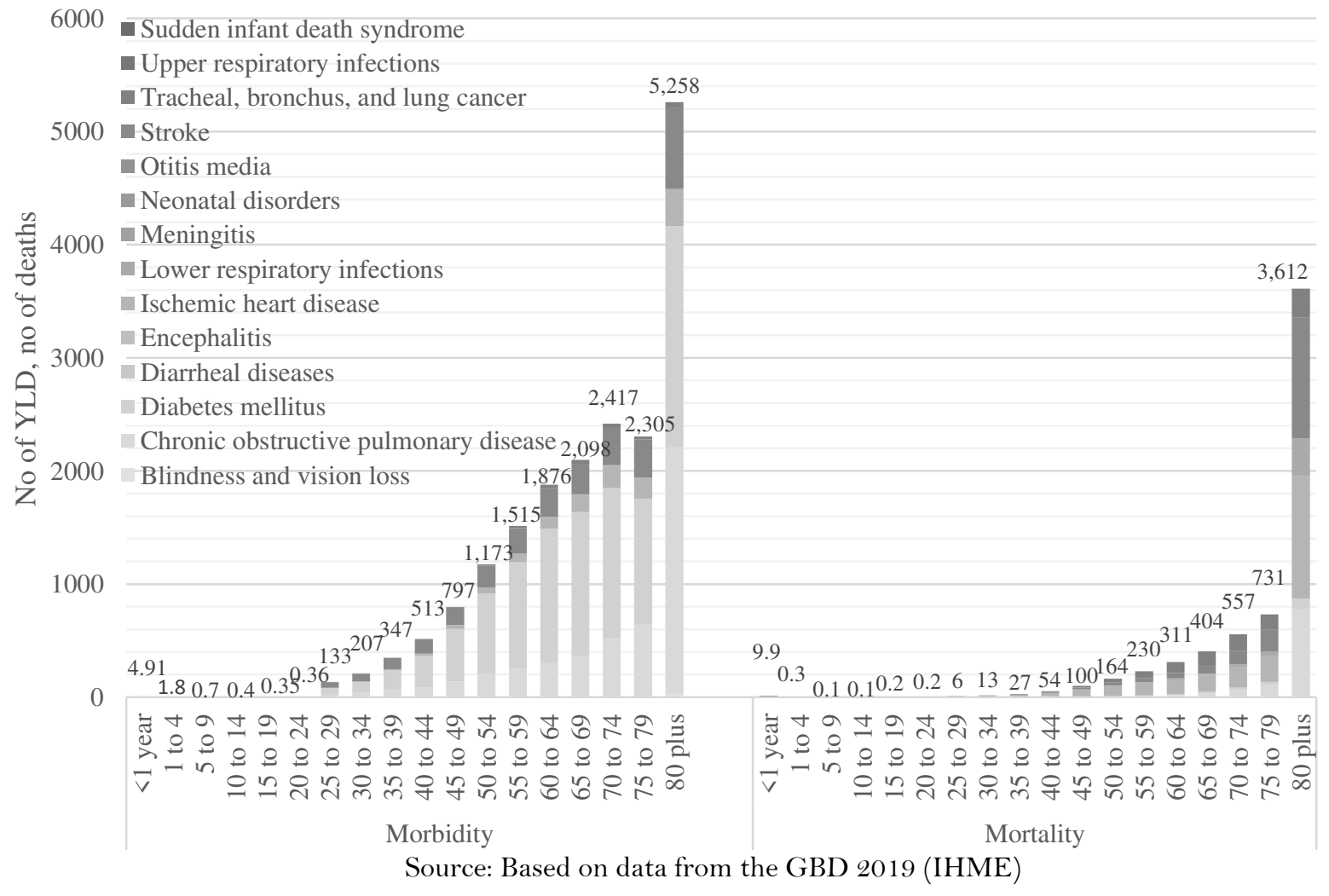


Figure A3. Morbidity cost from ambient $\mathrm{PM}_{2.5}$ air pollution by age and gender, Greece, 2019

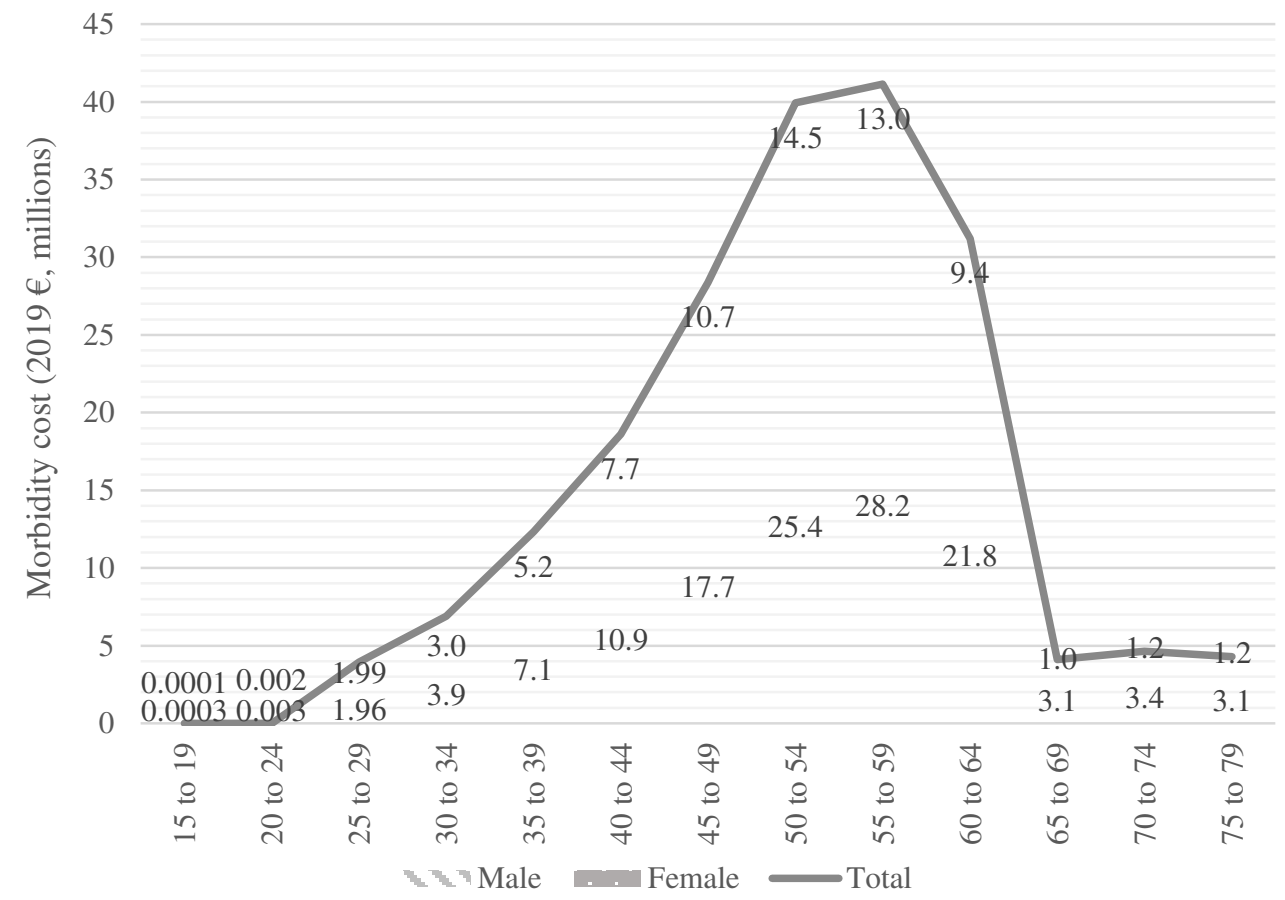

Source: Own calculations based on data from the GBD 2019 (IHME), IMF and ILO

Figure A4. Morbidity cost from household $\mathrm{PM}_{2.5}$ air pollution by age and gender, Greece, 2019

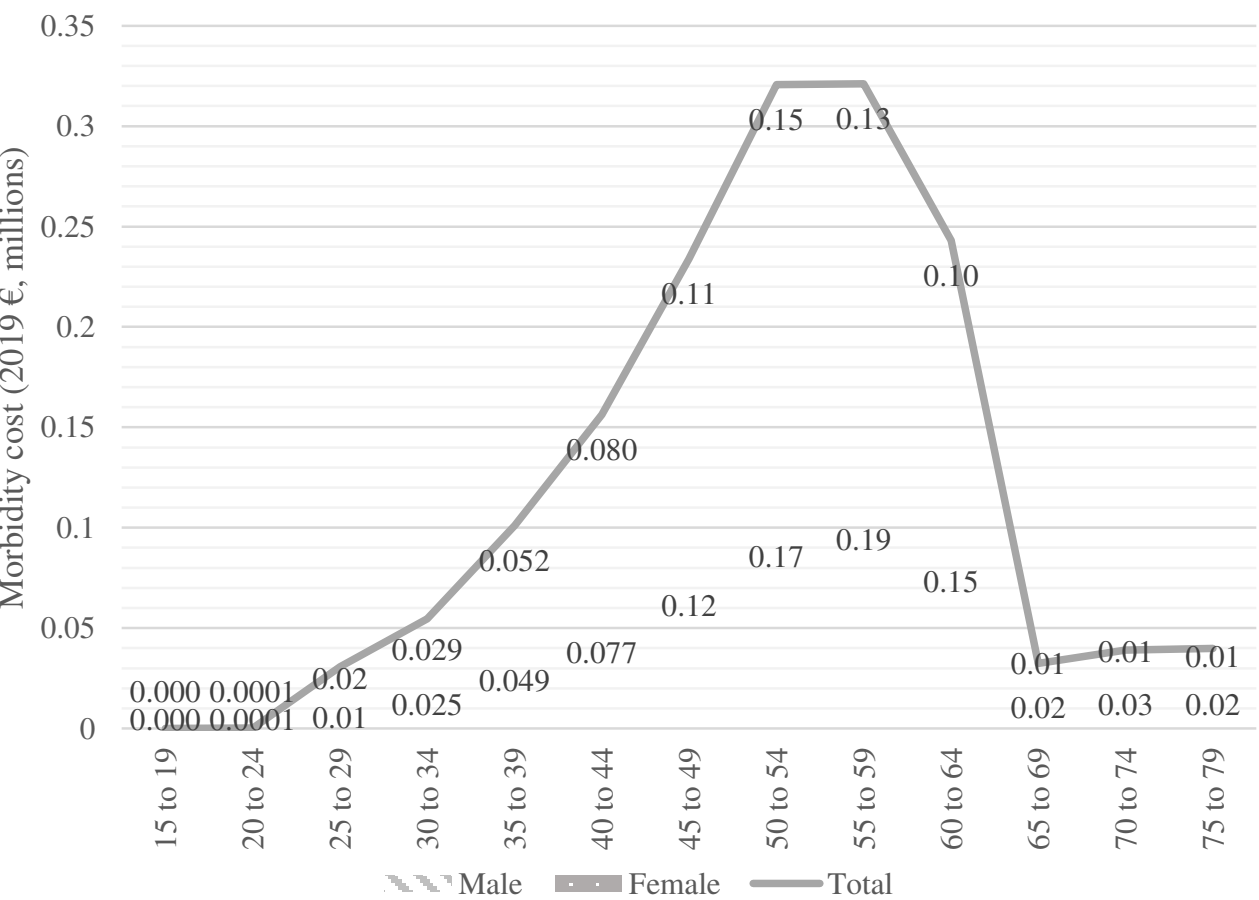

Source: Own calculations based on data from the GBD 2019 (IHME), IMF and ILO 
Figure A5. Mortality cost from ambient $\mathrm{PM}_{2.5}$ air pollution by age and gender, Greece, 2019

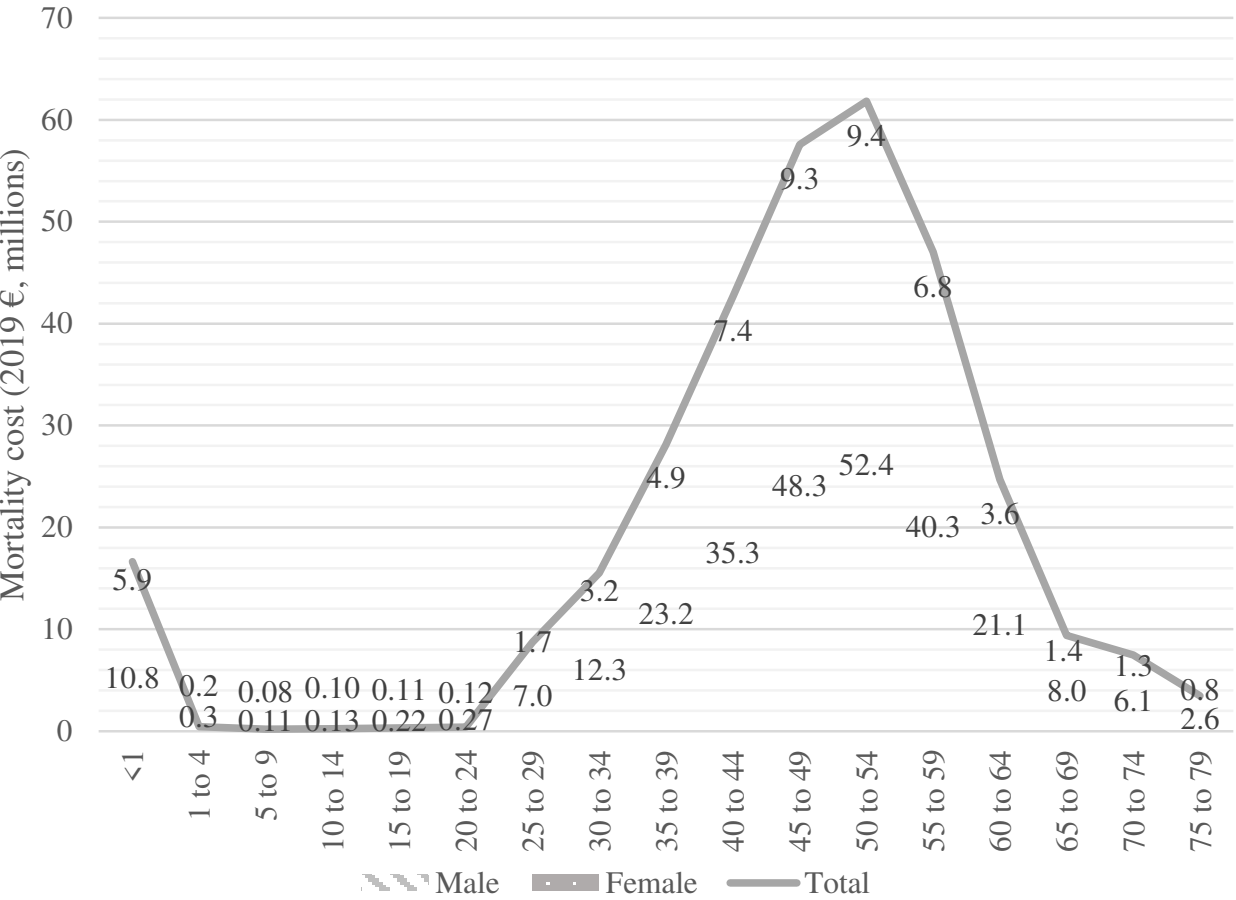

Source: Own calculations based on data from the GBD 2019 (IHME), IMF and ILO

Figure A6. Mortality cost from household $\mathrm{PM}_{2.5}$ air pollution by age and gender, Greece, 2019

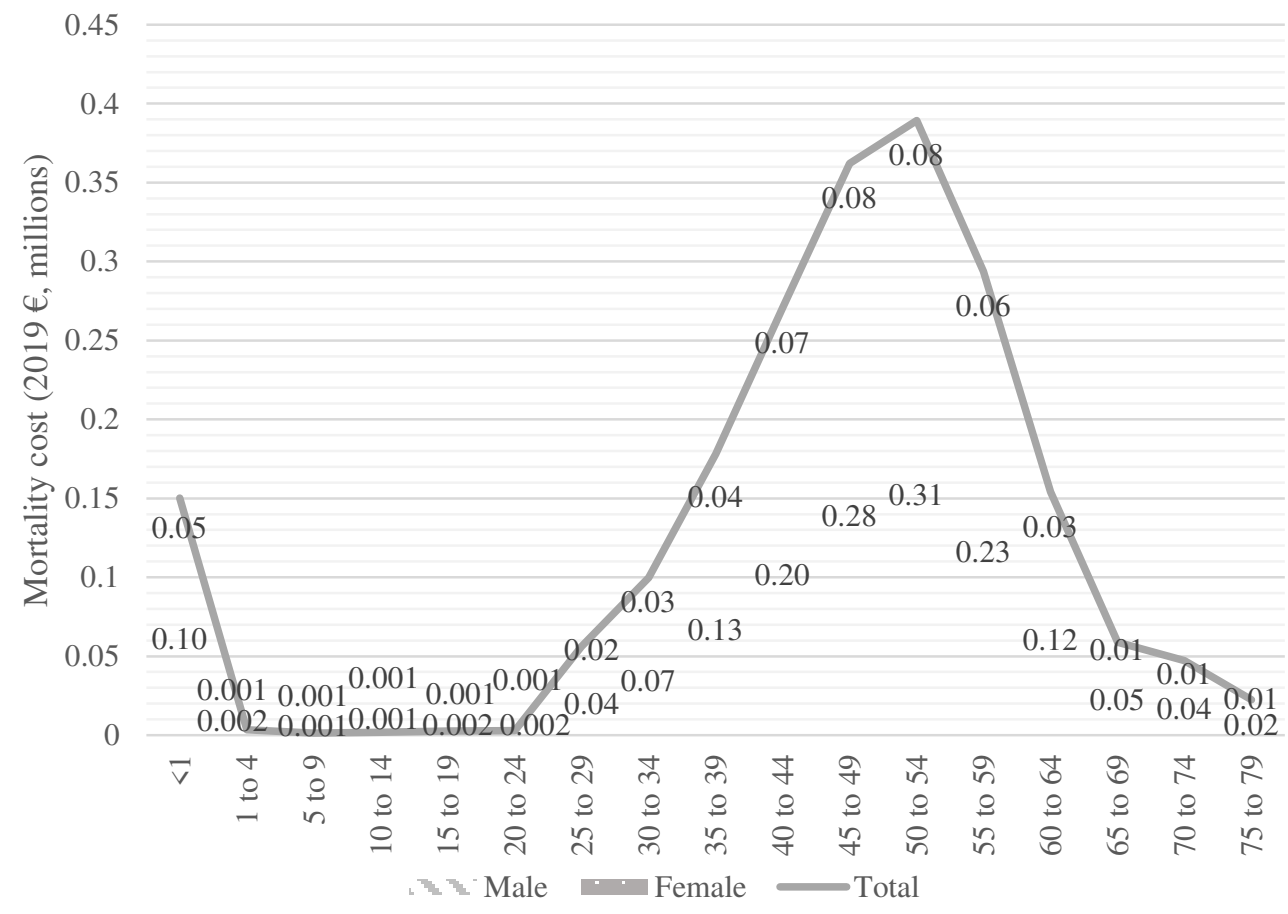

Source: Own calculations based on data from the GBD 2019 (IHME), IMF and ILO 
Figure A7. Mortality cost from ambient ozone air pollution by age and gender, Greece, 2019 1.2

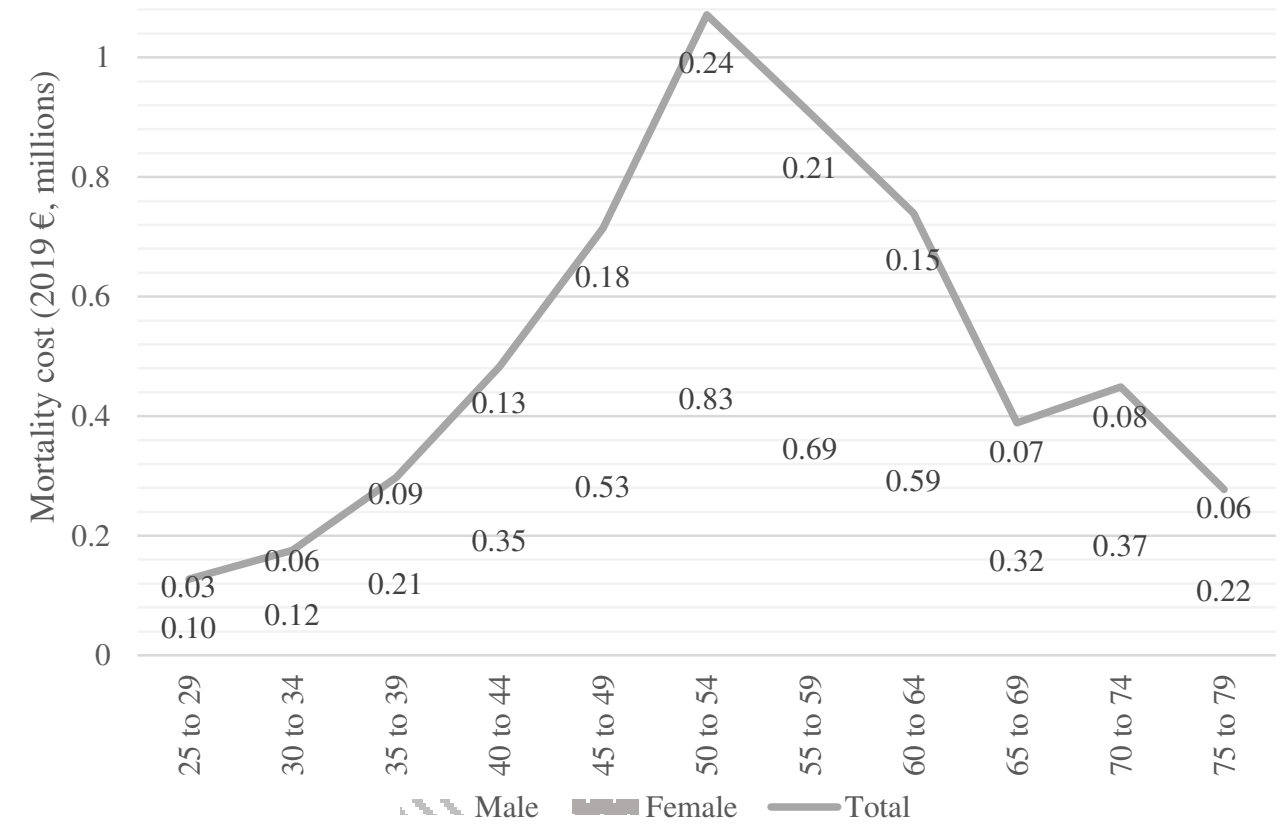

Source: Own calculations based on data from the GBD 2019 (IHME), IMF and ILO

This is an Open Access article distributed under the terms of the Creative Commons Attribution Licence 